\section{Self-reported adverse reactions associated with topical ophthalmic medication use: a cross-sectional survey}

\author{
Samuel Kyei, ${ }^{1}$ George Asumeng Koffuor, ${ }^{2}$ \\ Elvis Ofori Ameyaw, ${ }^{3}$ Paul Ramkissoon, ${ }^{4}$ \\ Daniel Adu-Agyeman ${ }^{1}$ \\ ${ }^{1}$ Department of Optometry, School of \\ Physical Sciences, University of Cape \\ Coast, Ghana; ${ }^{2}$ Department of \\ Pharmacology, College of Health \\ Sciences, Faculty of Pharmacy and \\ Pharmaceutical Sciences, Kwame \\ Nkrumah University of Science and \\ Technology, Kumasi, Ghana; ${ }^{3}$ Department \\ of Biomedical and Forensic Sciences, \\ School of Biological Sciences, University \\ of Cape Coast, Ghana; ${ }^{4}$ Discipline of \\ Optometry School of Health Sciences, \\ College of Health Sciences, University of \\ KwaZulu Natal, South Africa
}

\section{Abstract}

The aim of this study was to investigate selfreported adverse reactions associated with the use of topical ophthalmic medications. A crosssectional survey, involving 500 ophthalmic patients recruited from three eye care facilities in the Central Region of Ghana was conducted. A structured questionnaire was administered to participants to collect data on demographics, name of drug, dosage form, and dosing frequency of ophthalmic medications used, as well as adverse reactions experienced. The $\mathrm{pHs}$ of frequently prescribed ophthalmic medications to the patients were measured. The prevalence of reported adverse drug reaction [predominantly burning sensation (55\%), blurry vision (22\%) and itching (13\%)] was $44.8 \%$. More Females reported adverse drug reactions than males $\left(\chi^{2}=26.24, \mathrm{P}<0.001\right)$. The aged reported more adverse reaction than others $(\mathrm{P}<0.01)$. Patients using cream ophthalmic medications reported more adverse drug reactions than those using other dosage forms $\left(\chi^{2}=8.80, \mathrm{P}=0.024\right)$. The pHs of the commonly prescribed ophthalmic medications measured ranged between 4.447.37 (desired: 6.6-7.8). There is a high prevalence of reported symptoms of adverse drug reactions among this clinical population attributable to the acid/base status of the drug agent.

\section{Introduction}

In modern-day medicine, drug related adverse reactions and adverse drug reaction prevention strategies are evolving areas of concern, in therapeutics. ${ }^{1}$ One objective in the production of medication is to promote good health outcome with nominal adverse drug reactions. Adverse reaction can be detected at the pathological or physiological level. It may also be indicated by symptoms reported by medication users. ${ }^{2}$

Routes of drug administration have been studied to be among the determinants of adverse effects of medications. ${ }^{3}$ Results from clinical trials indicates there are minimal effects associated with some specific routes of administration (local administration), though this doesn't rule out the fact, that there are still adverse effects associated with each route of administration. ${ }^{4}$ In ocular pharmacology, topical ophthalmic medications compared to their systemic counterparts have less adverse effect though they cause local toxicity, hypersensitivity reactions and some systemic toxicity. ${ }^{2}$ The differences in age, gender and pigmentation melanin are also disparities that create differences in the outcome of administered pharmacological agents, especially ophthalmic agents, in different populations. Studies show that binding of drugs to melanin is the cause of multitude of pathophysiological or toxic effects in biological systems. ${ }^{5-8}$ Therefore, the need for community by community and possibly person by person reports of experienced of adverse drug reaction.

There are widespread reports of under reporting of adverse drug reaction using the existing conventional approaches. There is therefore a strong advocacy for intensive data collection on ADRs that were not reported to the relevant local, regional or national spontaneous reporting systems. ${ }^{9}$ This study therefore sought to investigate self-reported adverse reactions associated with topical ophthalmic medication use by patients recruited from three eye care facilities in the Central Region of Ghana.

\section{Materials and Methods}

\section{Study site}

The Central Region of Ghana one of ten administrative regions renowned for its many elite higher education institutions and an economy based on an abundance of industrial minerals and tourism. The Region has an estimated population of $2,107,107$ according to the 2010 national population census. There are 193 health facilities with 16 eye clinics situated in some of these facilities. ${ }^{10,11}$ Participants in this study were patients reporting to the Eye Units/Clinics of the Central Regional Hospital, Bishop Ackon Memorial Christian Eye Center and Our lady of Grace Hospital, Breman Esikuma; major eye care facilities in the
Correspondence: Samuel Kyei, Department of Optometry, School of Physical Sciences, University of Cape Coast, Cape Coast, Ghana.

Tel.: +23.324.330.9718.

E-mail: skyei@ucc.edu.gh

Key words: ophthalmic medications, adverse events, burning sensation, Ghana.

Contributions: the authors contributed equally.

Conflict of interests: the authors declare no potential conflict of interests.

Received for publication: 30 December 2013

Revision received: 24 March 2014.

Accepted for publication: 31 March 2014.

This work is licensed under a Creative Commons Attribution NonCommercial 3.0 License (CC BYNC 3.0).

@C Copyright S. Kyei et al., 2014

Licensee PAGEPress, Italy

Drugs and Therapy Studies 2014; 4:5278

doi:10.4081/dts.2014.5278

Region with the full complement of eye care staff providing one stop optical, medical and surgical eye care services to the people within the region.

\section{Study population and sample size}

Five Hundred (500) patients were evenly recruited from these eye clinics as the average annual records of attendance (about 8000) to these facilities were almost the same. The minimum sample size for the survey was determined as quoted by Glenn, ${ }^{12}$ using the formula developed by Cochran (1963:75):

Where:

$$
\mathrm{N}_{0}=\mathrm{Z}^{2} \mathrm{pq} / \mathrm{e}^{2}
$$

- $\mathrm{N}_{0}$ is the sample size

- $\mathrm{Z}^{2}$ is the abscissa of the normal curve that cuts off an area $\alpha$ at the tails ( 1 - $\alpha$ equals the desired confidence level)

- $\mathrm{e}$ is the desired level of precision

- $p$ is the estimated proportion of an attribute that is present in the population

- $\mathrm{q}$ is 1-p.

Therefore assuming that $50 \%$ of the patients who come to the eye center will be available for the survey, taking a confidence level of $95 \%$ and a sampling error of 5\% minimum sample size computed was 384.12 . However, the sample size was adjusted to 500 . The participants were conveniently recruited and interviewed with a structured questionnaire. Selection included only review patients who had used an ophthalmic preparation within the month prior to the study mainly to avoid recall bias. 


\section{Definition of terms}

World Health Organization's definition of an adverse drug reaction (ADR), is a response to a drug that is noxious and unintended and exist in doses normally used in humans for prophylaxis, diagnosis or therapy for disease, or for modification of physiological function. ${ }^{13}$

Adverse drug reactions have been variously characterized by based on definitive features into types A-H and U. Type A (augmented) reactions are considered to be an exaggeration of the medicine's normal effect when given at the usual dose and predictable. Type B (bizarre) reactions are effects that are not pharmacologically predictable and can include hypersensitivity reactions. Type $\mathrm{C}$ (chronic) reactions describe those that persist for a relatively long time, type D (delayed) reactions, which become apparent some time after the use of a medicine, type $\mathrm{E}$ (end of use) reactions are associated with the withdrawal of a medicine. The other classes are Type F (failure), type G (genetic/genomic), type $\mathrm{H}$ (hypersensitivity) and type $\mathrm{U}$ (unclassified). ${ }^{14,15}$ Type A which includes side effects is the most common. ${ }^{14,15}$

A self-report study is a type of survey, questionnaire, or poll in which respondents read the question and select a response by themselves without researcher interference. A selfreport is any method which involves asking participants about their feelings, attitudes, beliefs etc. Questionnaires and interviews are normally used in self-report study. ${ }^{16}$

\section{Study design}

The study was a cross sectional survey using a pre tested questionnaire. The questionnaire had three sections: i) Section A featured items on age of the respondent, the gender, and the occupation of the respondent; ii) Section B sought the name of drug used, the ocular condition for drugs were used for, the dosage form of the drug, and frequency of application; iii) Section C sought the side effect(s) experienced during use of topical medication and the onset of the symptoms of ADRs.

The $\mathrm{pH}$ of the ophthalmic medications used by respondents were taken using a $\mathrm{pH}$ meter (Denver instrument GmbH, Germany) and the mean \pm SD $(n=3)$ computed and recorded. The selected medications were based on their frequency of prescription. The medications and the manufacturing companies were coded since some medications were branded.

\section{Ethical considerations}

The research was done according to the Helsinki Declaration on Research regarding Human Subjects. Permission was sought from the heads of Central Regional Hospital, Bishop Ackon Memorial Christian Eye Center and Our lady of Grace Hospital, Breman Esikuma. To obtain consent of the respon- dents, a detailed explanation of the aim and objectives of the study was given, after which respondents signed a consent form. Confidentiality was ensured by random coding of the questionnaires.

\section{Data analysis}

All the variables were coded, entered, and analyzed using the statistical package for social sciences (SPSS) v.19 for Windows (Chicago, USA). Descriptive results were expressed as frequency, percentage, and mean \pm SD. Chi-square statistical analysis was used to test for associations between variables. $\mathrm{P} \leq 0.05$ was considered significant.

\section{Results}

Out of the 500 participants, 304 (60.8\%) of were females and 196 (39.2\%) were males. The age range of participants was from 15 to 89 years with a mean age of $50.12 \pm 18.42$. The age distribution was as follows: adolescence and early adulthood (15-29), [102, (20.4\%)], adulthood (30-49), [99, (19.8\%)] and the elderly (50 and above), [299, (59.8\%)]. ${ }^{17,18}$ The participants were predominantly farmers [155 (31.0\%)], traders [100 (20\%)], and students [80 (16.4\%)]. The others included welders, teachers, nurses, drivers, hairdressers.

Two hundred and twenty four (44.8\%) of the patients experienced adverse reactions with the application of topical ocular medication; more females [164 (73.2\%); $\left.\chi^{2}=26.24 ; \mathrm{P}<0.001\right]$ reported adverse drug reactions than males 60 (26.7\%). Of the 278 reported symptoms of ADRs, burning sensation, 153 (55\%) was the most prevalent, followed by blurry vision 60 (22\%) and itching 36 (13.0\%) (Table 1).

Results indicated a positive relationship $(\mathrm{r}=0.16, \mathrm{P}<0.01)$ between age and reported symptoms of ADRs; the elderly were more likely $\left(\chi^{2}=20.494, P<0.01\right)$ to report symptoms of
ADRs. There was however, no significant association $\left(\chi^{2}=19.71, \mathrm{P}=0.140\right)$ between occupation and symptoms of ADRs experienced.

The vast majority of the patients were prescribed ophthalmic solutions [449 (89.6.0\%)], followed by ointments [24 (4.8\%)], suspensions [24 (4.8\%)], and creams [3 (0.6\%)]. The frequency of administration range from once daily to six times daily. There was no association between frequency of application and symptoms of reported ADRs $\left(\chi^{2}=11.31\right.$, $\mathrm{P}=0.069$ ). There was however a significant association between the dosage form and side effects reported $\left(\chi^{2}=8.80, \mathrm{P}=0.024\right)$ (Table 2$)$.

The three most frequently prescribed ophthalmic drugs were Maxitrol (combination of dexamethasone, neomycin and polymycin B), 55 (11.0\%), Timolol maleate, $43(8.6 \%)$ and Gentamycin 27, (5.4\%) (Table 3). The pH of the reported medications obtained from the eye care facilities ranged from 4.44 to 7.37 (Table 4).

\section{Discussion}

Self-reported studies apart from being cheap in terms of cost and time have the unique advantage of measuring constructs that are difficult to obtain with behavioral or physiological measures. It can also be done easily on a large scale. Nevertheless it has validity challenges as participant may exaggerate or under report symptoms, recall bias and misinterpretation of questions. ${ }^{19}$ The bottle neck associated with this method was minimized by recruiting only review patients who had used an ophthalmic preparation within the month prior to the study. The questionnaire was also pretested among review patients in two different eye care facilities to ensure reliability before final field administration. Fifty review patients 25 each from the Department of Optometry clinic and the Bisphop Ackon

Table 1. The prevalence of the 278 reported symptoms of adverse drug reactions and severities.

\begin{tabular}{lcccc} 
Side effects & Prevalence (\%) & Mild (\%) & Moderate (\%) & Severe (\%) \\
Itching & $36(13)$ & $33(91.7)$ & $3(8.3)$ & - \\
Redness & $2(1)$ & $2(100)$ & - & - \\
\hline Photophobia & $4(1)$ & $3(75.0)$ & - & $1(25.0)$ \\
Headache & $9(3)$ & $5(55.6)$ & $2(22.2)$ & $2(22.2)$ \\
\hline Blurry vision & $60(22)$ & $50(83.3)$ & $4(6.7)$ & $6(10.0)$ \\
Seeing double & $3(1)$ & $2(66.7)$ & $1(33.3)$ & - \\
\hline Tearing & $4(1)$ & $4(100.0)$ & - & - \\
Nausea & $5(2)$ & $3(60.0)$ & $2(88.4)$ & - \\
\hline Burning sensation & $153(55)$ & $137(27.4)$ & $10(6.5)$ & $8(5.2)$ \\
Slow heart rate & $2(1)$ & $2(100.0)$ & - & - \\
\hline
\end{tabular}


Memorial Christian Eye Centre completed the questionnaire. Inconsistent responses to three of the test items were noted which was later modified for a second round of pretest. Cronbach's alpha for reliability was estimated to be 0.7 . The finding of this study should therefore be extrapolated with caution. There is no available data on adverse drug reactions
(ADRs) associated with use of topical ophthalmic preparation is Ghana. This could be due to ineffectiveness of the conventional approaches of reporting of ADRs. ${ }^{9}$ This therefore, provides a baseline data on symptoms of ADRs of topical ophthalmic preparations.

The gender inequality could be due to chance or due to the fact that there are gener-

Table 2. Distribution of dosage form and side effects.

\begin{tabular}{lccc} 
Dosage form & Usage & \multicolumn{2}{c}{$\begin{array}{c}\text { Adverse reactions reported } \\
\text { Yes (\%) }\end{array}$} \\
Solution & 449 & $194(38.8)$ & $255(50.1)$ \\
Ointment & 24 & $11(45.8)$ & $13(54.2)$ \\
\hline Cream & 3 & $3(100)$ & $0(0.0)$ \\
Suspension & 24 & $16(66.7)$ & $8(33.3)$ \\
Total & 500 & $224(44.8)$ & $276(55.2)$
\end{tabular}

Proportions were compared using a two-tailed $\chi^{2}$ test; $\mathrm{P} \leq 0.05\left(\chi^{2}=8.80, \mathrm{df}=2, \mathrm{P}=0.024\right)$.

Table 3. Details of the reported ocular medication prescribed to the 500 respondents.

\begin{tabular}{lccc}
\hline Drug & Frequency (\%) & Drug & Frequency (\%) \\
Acculol & $4(0.8)$ & Maxipsorin & $3(0.6)$ \\
Alrex & $19(3.8)$ & Neomycin & $8(1.6)$ \\
\hline Alphagan & $3(0.6)$ & Nostamine & $7(1.4)$ \\
Atropine & $2(0.4)$ & Timolol & $43(8.6)$ \\
\hline Chloramphenicol & $2(0.4)$ & Patanol & $1(0.2)$ \\
Ciprofloxacin & $14(2.8)$ & Prednisolone & $13(2.6)$ \\
\hline Cool Eyes & $7(1.4)$ & Tears & $7(1.4)$ \\
Dexatrol & $14(2.8)$ & Tetracycline & $12(2.4)$ \\
\hline Epicrom & $14(2.8)$ & Tobradex & $5(1.0)$ \\
Epifenac & $4(0.8)$ & Xalatan & $6(1.2)$ \\
Gentamycin & $27(5.4)$ & Maxitrol & $55(11.0)$
\end{tabular}

Table 4. The $\mathrm{pH}$ of the commonly prescribed of the list of the ophthalmic medication recorded.

\begin{tabular}{lcl} 
Drug & Manufacturer & pH \\
$\lambda$ & A & $6.72 \pm 0.03$ \\
$\infty$ & B & $6.85 \pm 0.06$ \\
\hline$\propto$ & C & $4.63 \pm 0.05$ \\
$\alpha$ & D & $6.44 \pm 0.05$ \\
\hline$\beta$ & E & $5.64 \pm 0.03$ \\
$\gamma$ & E & $5.85 \pm 0.06$ \\
\hline$\rho$ & E & $7.37 \pm 0.03$ \\
$\sigma$ & F & $4.40 \pm 0.05$ \\
\hline$\phi$ & E & $6.19 \pm 0.01$ \\
$\omega$ & G & $6.00 \pm 0.04$ \\
\hline$\psi$ & D & $6.80 \pm 0.04$ \\
$\omega$ & G & $5.59 \pm 0.02$ \\
\hline$\underline{y}$ & D & $5.78 \pm 0.05$
\end{tabular}

$\lambda, \infty, \propto, \alpha, \beta, \gamma, \rho, \sigma, \phi, \omega, \psi, \omega$ and $\underline{y}$ are notations for selected medications tested for $\mathrm{pH}$ among the reported medication prescribed to participants. A, B, C, D, E, F and $\mathrm{G}$ are the manufacturing companied coded to mask their identity. Values are Mean $\pm \mathrm{SD}(\mathrm{n}=3)$.

ally more females than males, as reported by 2010 Census. ${ }^{10}$ This difference in the number of females outweighing males could also be due to the likelihood of women to report to the hospital with several complaints than men. ${ }^{20}$ In relation to age, it was evident that the most prevalent age group was the elderly and they reported the highest adverse effects. The high likelihood of an elderly person to report adverse drug reaction could be due to age-related changes in drug metabolism and excretion, coupled with the co-morbidity and polypathology often associated with ageing. ${ }^{21}$ The onset of these symptom ADRs was noted within the first 10 minutes after the drug application. The short duration within which the participant experienced these symptoms is indicative that they were due to the applied agent.

Most of the participants who were involved in this study mainly belonged to the agricultural sector. These included crop farmers, which was the highest reported occupation, fisherman, fishmongers etc. Other notable occupations include traders, students, teachers and a few others. The kind of occupation one was engaged in had no effect on the influence on the adverse effect reported.

The prevalence of adverse reaction was high as nearly half of the participant reported of adverse drug reaction in this study. Burning sensation was the most common symptoms of adverse reaction associated with the use of topical ophthalmic medications. ${ }^{22}$ The major attributable factor for this occurrence is intolerance of the human eye to these topical preparations. $^{22,23}$ Topical ophthalmic medications should have minimum irritation or stinging to the eye, thus, should have $\mathrm{pH}$ ranges which are suitable to the eye, nevertheless, ${ }^{22}$ several studies elsewhere have reported stinging, burning, redness, and tearing on ocular instillation of most topical ophthalmic preparations such as sodium cromoglycate e.g. Epicrom, olopatadine e.g. Patanol etc. ${ }^{24,25}$

The $\mathrm{pH}$ of tears is 7.4. ${ }^{26}$ However, the eye can perfectly tolerate drugs within the ranges of 6.6 and 7.8 and any medication which falls outside this could cause discomfort in the eye. ${ }^{22,23}$ Most commonly prescribed topical medication reported by the participants had pHs outside the tolerable range (Table 4). Unfortunately, estimates from the World Health Organization indicated that only about $50 \%$ of patients with chronic diseases living in developed countries follow treatment recommendation, ${ }^{27}$ due to the complexity of modern medication regimen of which $\mathrm{pH}$ variations of drugs are inclusive. Most of the reported side effects were local with only a few systemic adverse effects. ${ }^{28-31}$ The adverse drug reactions were mainly type A. ${ }^{32}$ In this study, there was no significant association between symptoms of adverse drug reaction and the frequen- 
cy of drug application. This supports pharmacologic analysis of drug adverse reaction in that, the occurrence of a certain side effect is irrespective of the times a person applies the drug but rather dose dependent. Frequency of application therefore doesn't play a major role in the incidence of adverse drug reactions. Risk factors that influence side effects include dose, pregnancy, age, duration of application. ${ }^{33}$

There is a dearth of information on the association between ocular dosage forms and adverse reaction. However, this study established an association between the dosage form and the report of symptoms of adverse reactions. It is pretty obvious that the variation in contact time with regards to the various dosage forms of topical ophthalmic preparations could be the critical factor. ${ }^{34}$

The high prevalence of burning sensation reported in this study rather suggests that the important factor is the acid/base status of the drug agent. ${ }^{35}$

\section{Conclusions}

There is a high prevalence of reported symptoms of adverse drug reactions among this clinical population studied attributable to the acid/base status of the drug agent. It is therefore, recommended that pharmaceutical industry reconsider the ocular tolerability of their products to curb the soaring incidence of non compliance that could result from drug related factors.

\section{References}

1. Izazola-Conde C, Zamora-de la Cruz D, Tenorio-Guajardo G. Ocular and systemic adverse effect of ophthalmic medications. Proc West Pharmacol Soc 2011;126:68-71.

2. Egyptian Pharmacovigilance Centre (EPVC). Guidelines for detecting adverse drug reaction in Egypt. Individual case safety reports for health care professionals. 2010. Available from: http:/www.scribd.com/ doc/78256321/Egyptian-Guideline-on-ADRReporting-for-Healthcare-Professionals-1512-2011-Version-01

3. Aloomar MJ. Factors affecting the development of adverse drug reactions (Review article). Saudi Pharm J 2014;22:83-94.

4. Lee S, Glendenning $P$, Inderjeeth CA. Efficacy, side effects and route of adminis- tration are more important than frequency of dosing of osteoporosis treatments in determining patient adherence: a critical review of published articles from 19702009. Osteoporos Int 2011;22:741-53.

5. Beard K. Adverse reactions as a cause of hospital admission in the aged. Drug Aging 1992;2:356-67.

6. Cheruvu PSN, Amrite AC, Kompella UB. Effect of eye pigmentation on transscleral drug delivery. Invest 0phthalmol Vis Sci 2008;1:33-341.

7. Wang Y, Casadevall A. Susceptibility of melanized and non melanized crptococcus neoformans to the melanin compounds trifluoperzine and chloroquine. Antimicrob Agent Chemother 1996;40:541-5.

8. Howells L, Miquel G, Sauer MJ. Malanin as an absorbent for drug residue. Anayst 1994;119:2691-3.

9. Hazell L, Shakir SA. Under-reporting of adverse drug reactions: a systematic review. Drug Saf 2006;29:385-96

10. Ghana Health Service. Regional publication (2010). Available from: http://www. ghanahealthservice.org/documents/Annua 1\%20Report\%202010\%20CR\%20.pdf

11. Ghana Health Service. Regional publication (2011). Available from: http://www. ghanahealthservice.org/documents/Annua 1\%20Report\%202011\%20CR.pdf

12. Israel GD. Determining sample size. Sampling the evidence of extension program impact, PEOD-5 1992. Available from: http://edis.ifas.ufl.edu/pd006. Accessed on: June, 2013.

13. Ralph EI, Aronson JK. Adverse drug reaction: definitions, diagnosis and management. Lancet 2000;356:1255-9.

14. Rawlins M, Thompson W. Mechanisms of adverse drug reactions. In: Davies D, ed. Textbook of adverse drug reactions. New York: Oxford University Press; 1991. pp 18-45.

15. Wills S, Brown D. A proposed new means of classifying adverse drug reactions to medicines. Pharm J 1999;262:163-5.

16. Thronberry TP, Krohn MD. The self-report method for measuring delinquency and crime. 2000. Available from: https:/www. ncjrs.gov/criminal_justice2000/vol_4/04b.pdf

17. World Health Organization. Health statistics and health information systems. 2013. Available from: www.who/int/healthinfo/ survey/ageingdefnolder

18. Geiger AM, Catellino SM. Delineating the age ranges used to define adolescence and young adult. Am Soc Clin Oncol 2011; 29:16.

19. Fielding NG. Self-report study. The SAGE dictionary of social research methods. 2006.

20. Arthur JB, Peekna HM, Borus JF. Somatic symptoms symptom reporting in women and men. J Gen Intern Med 2001;16:266-75.

21. Routledge PA. Adverse reactions in elderly patients. Br J Clin Pharmacol 2003;57:121-6.

22. Duval B, Keshner R. Ophthalmic medications and pharmacology. $2^{\text {nd }}$ ed. Thorofare: Slack Inc.; 2002.

23. Stein HA, Slatt BJ. The ophthalmic assistant: fundamentals and clinical practice. $5^{\text {th }}$ ed. London: CV Mosby Co; 1971.

24. Barranco P, Dominguez C, Lopez-Serrano C, Cabañas R. Local reaction to ocular disodium cromoglycate. Allergy 1996;51:133-4.

25. Soparkar CN, Wilhelmus KR, Koch DD, et al. Acute and chronic conjunctivitis due to over-the-counter ophthalmic decongestants. Arch Ophthalmol. 1997;115:34-8.

26. Fischer FH, Wiederholt M. Human precorneal tear film $\mathrm{pH}$ measured by microelectrodes. Graefes Arch Clin Exp Ophthalmol 1982;218:168-70.

27. World Health Organization. Adherence to long-term therapies: evidence for action. 2003. Available from: http://whqlibdoc.who. int/publications/2003/9241545992.pdf

28. Servat JJ, Bernardino CR. Effects of common topical antiglaucoma medications on the ocular surface, eyelid and periorbital tissue. Drug Aging 2011;28:267-82.

29. Goldberg I, Moloney G, McCluskey P. Topical ophthalmic medication: what potential for systemic side effects and interactions with other medications? Med J Austral 2008;189:356-7.

30. Detry-Morel M. Side effect of ocular glaucoma medications. Bull Soc Belge Ophthalmol 2006;499:27-40.

31. Shiuey Y, Elsenberg MJ. Cardiovascular effects of commonly used ophthalmic medications. Clin Cardiol 1996;19:5-8.

32. Meyboom RHB, Lindquist M, Egberts ACG. $\mathrm{An} \mathrm{ABC}$ of drug related problems. Drug Saf 2000;22:415-22.

33. Tarloff JB. Risk factors for adverse drug reactions. The Mercks manual health handbook. 2012. Available from: http:// www.merckmanuals.com/home/drugs/adve rse_drug_reactions/risk_factors_for_adve rse_drug_reactions.html

34. Uchegbu IF, Florence AT. Adverse drug events related to dosage forms and delivery systems. Drug Saf 1996;14:39-67.

35. Leblanc B, Jezequel S, Davies T, et al. Binding of drugs to eye melanine is not predictive of ocular toxicity. Regul Toxicol Pharmacol 1998;28:124-32. 